\title{
Da Cidade Inteligente, ao Território Inovador, Rumo à Inteligência Territorial Aproximações Teóricas e Prospecções sobre o Tema
}

\author{
http://dx.doi.org/10.21527/2237-6453.2020.53.46-71
}

Recebido em: $12 / 5 / 2020$

Aceito em: 30/7/2020

Valdir Roque Dallabrida ${ }^{1}$

\begin{abstract}
RESUMO
O debate teórico sobre inovação e sua relação com o desenvolvimento, geralmente com foco no espaço urbano, tem resultado em diferentes abordagens sobre cidades inteligentes. As mesmas são passíveis de críticas, como o fato de as prerrogativas não serem replicáveis, a ênfase excessiva ao argumento do desenvolvimento urbano ser impulsionado por negócios privados em aliança com governos e sociedade, ou o fato de as experiências carecerem de práticas inclusivas e participativas. Já a abordagem sobre território inovador ou inteligente permite avançar teoricamente, oportunizando a interação social para as tomadas de decisão e a valorização e apropriação territorial do conhecimento. Complementarmente, os enfoques teóricos sobre inteligência territorial são apresentados como uma inovadora forma de compreender os processos territoriais, produtivos e sociais, de integrar atores e suas perspectivas, visões e iniciativas, com vistas ao desenvolvimento territorial. É sobre estas questões teóricas que se pretende refletir, por meio do acesso às publicações recentes, com o propósito de instigar acedências na direção da efetividade de uma inteligência territorial.
\end{abstract}

Palavras-chave: Inovação. Cidades inteligentes. Território inovador. Inteligência territorial. Desenvolvimento territorial. FROM THE SMART CITY TO THE INNOVATIVE TERRITORY, TOWARD THE TERRITORIAL INTELLIGENCE:
THEORETICAL APPROACHES AND PROSPECTIONS ABOUT THE SUBJECT

\begin{abstract}
The theoretical debate about innovation and its relation with the development, generally focused in the urban space have resulted in different approaches about smart cities. These are liable of criticism, like the fact of non-replicable prerogatives, the excessive emphasis to the argument of urban development be promoted by private businesses in coalition with the government and society, or the fact of the need of inclusive and participative experiences. The approach about innovative or smart territory allows to advance theoretically, giving opportunity to social interaction for the decision-making and the appreciation and territorial appropriation of knowledge. Complementary, the theoretical approaches about territorial intelligence are presented as an innovative way of understanding the territorial, productive and social processes, by integrating actors and their expectations, vision and initiative, aiming to territorial development. It is about these theoretical questions that is proposed to reflect, by the access to recent publishing, with the purpose of instigating accessions toward the effectiveness of a territorial intelligence.
\end{abstract}

Keywords: Innovation. Smart cities. Innovative territory. Territorial intelligence. Territorial development.

\footnotetext{
${ }^{1}$ Doutor em Desenvolvimento Regional pela Universidade de Santa Cruz do Sul (Unisc). Professor do Programa de Stricto Sensu em Desenvolvimento Regional (Mestrado e Doutorado) e Mestrado Profissional em Administração da Universidade do Contestado (UnC). Santa Catarina, Brasil. http://lattes.cnpq.br/1181379224202943. https://orcid.org/0000-0003-2927-960X. valdirdallabrida@gmail.com
} 
Toma-se como parâmetro para a abordagem sobre inovação a acepção proposta por Emmendoerfer (2019a), como processo que requer de indivíduos e organizações uma capacidade para permitir a identificação e a prática de ideias novas, aprimoradas ou renovadas, como referente na solução de problemas que impliquem melhor desempenho nos resultados esperados pelas administrações públicas, ou sociedade em geral, em termos de eficiência, eficácia e valor.

Em publicação recente argumenta-se que há uma relação intrínseca entre inovação, desenvolvimento e espaço urbano (DALLABRIDA; COVAS; COVAS, 2017). Questiona-se, no entanto, sobre em que contribuíram as variadas abordagens sobre o tema, com o fim de avançarmos enquanto civilização, considerando que essa relação não deve ser simplesmente instrumental e/ou funcional, uma vez que a cidade pode gerar inúmeras disfunções, quer no seu interior, quer no seu entorno territorial. Ou seja, levanta-se a hipótese de que temos cidades inteligentes e tecnologicamente avançadas, coexistindo em paralelo com cidades desiguais, guetizadas e civicamente pobres. Propunham os autores um padrão de desenvolvimento integrador, mais inteligente, mais inclusivo, mais eclético, isto é, eticamente mais responsável perante os seus cidadãos.

As interrogações apresentadas no referido texto serviram de motivação para aprofundar o tema. Após muitas leituras, consultando parte da literatura, chegou-se à conclusão de que valeria o esforço de recorrer a uma das abordagens, sobre a qual tem-se publicado um número acentuado de artigos ou livros: a cidade inteligente ou smart city. A motivação de escrever sobre o tema teve como propósitos básicos verificar: (i) como o tema é tratado e quais os argumentos básicos em que se sustenta tal abordagem; (ii) quais as principais críticas sobre a abordagem; e, finalmente, para não ficar somente na revisão do estado da arte, (iii) quais enfoques teóricos contemporâneos, que fazem a relação entre inovação e desenvolvimento, permitem avançarmos teórica e operacionalmente no sentido de superar as lacunas apontadas nas críticas.

Parte-se do entendimento de que a maioria dos lugares, das regiões ou territórios permanecem periféricos, estagnados e pouco conectados, tanto no sentido técnico quanto no estabelecimento de redes de contato nacional ou internacional. ${ }^{2} \mathrm{Ou}$ seja, continuam reproduzindo "mais do mesmo", replicando soluções experimentadas internacionalmente e que, no passado, até apresentaram resultados, ressentindo-se de um processo constante e inovador de planejamento, com participação plural. Quando se ensaiam processos de planejamento, privilegiam-se iniciativas conduzidas por consultorias de caráter empresarial, muitas vezes alheias aos debates recentes sobre planejamento que ocorrem nos meios acadêmicos.

Metodologicamente, considerando não ter a pretensão de esgotar o tema, nem conseguir abarcar toda a produção acadêmica, estabeleceu-se como critérios: (i) fixar-se em um conjunto de textos disponibilizados para acesso nas plataformas eletrônicas Academia.edu e Redalyc, além de outras publicações, indicados pelos autores consultados, e (ii) limitar a consulta a um número de publicações que permitisse sua síntese no tamanho exigido para um texto publicável em periódico científico. De um total de mais uma centena de publicações, foram selecionadas as que pareciam ter maior cen-

${ }^{2}$ Ver estudo publicado recentemente sobre o assunto: Dallabrida e Grein (2020). 
tralidade com o tema que se pretendeu estudar. Por fim, com base nessas contribuições teóricas é que se pretendeu avançar, fazendo um rápido contato com o debate sobre internet das coisas, mas detendo-se em contribuições teóricas com enfoque integrador, como sobre território inovador ou inteligente, avançando na instigação sobre a necessidade de efetivação do que se passou a chamar de inteligência territorial.

Assim, o presente artigo, ${ }^{3}$ além destas considerações introdutórias, está estruturado em mais quatro partes: (i) na primeira revisa-se o tema cidades inteligentes ou smart cities; (ii) na segunda destacam-se as principais críticas sobre o tema; (iii) na terceira, com caráter mais analítico-propositiva, propõe-se avançar no debate teórico, com o fim de orientar novas práticas; e, (iv) na última, são contempladas as considerações finais.

\section{CIDADES INTELIGENTES OU SMART CITIES}

Apesar da sinonímia, alguns autores referem-se ao termo smart city, enquanto outros às cidades inteligentes. Assim, trata-se do tema de forma conjunta, no entanto respeitando o uso feito pelos autores mencionados.

Segundo Aristizábal et al. (2018), o termo smart city, ou cidade inteligente, evoluiu no tempo: (i) wired cities - cidades interconectadas (DUTTON et al., 1987 ); (ii) digital cities - cidades digitais (ISHIDA; ISBISTER, 2000 ); (iii) cybercities - cibercidades (GRAHAM; MARVIN, 2001 ) e, por fim, (iv) intelligent cities ou smart cities - cidades inteligentes (KOMNINOS, 2002), termo que passou a ser o mais utilizado. ${ }^{4}$ Mais recentemente, o conceito de cidade inteligente tem variações, tais como cidade do conhecimento, cidade sustentável e cidade digital. Até a década de 90 do século 20, cidades digitais era o termo mais usado; hoje, o mais frequente é cidades inteligentes (NASClMENTO; SOUZA; SERRALVO, 2019).

O uso do termo smart city passou a ser mais reconhecido a partir de um informe da Comissão e do Parlamento Europeu do ano de 2012 (CE, 2012), em cujo texto enfatizava-se as características econômicas, educacionais, ambientais, de governança e mobilidade das chamadas cidades inteligentes, orientadas à qualidade de vida de seus habitantes.

A literatura que faz menção às cidades inteligentes, apesar do pouco consenso sobre o termo, em geral as concebem como as que integram as mais diferentes Tecnologias de Informação e Comunicação (TICS), com o fim de tornar as cidades atuais mais eficientes, sustentáveis e habitáveis (SUJATA; SAKSCHAM; TANVI, 2016). Para que ocorra esse avanço, é necessário aproveitar as potencialidades oferecidas pelas TICs para gerar ambientes territoriais nos quais sejam forjados "[...] núcleos de inovação e criatividade que favoreçam o crescimento econômico e a criação de emprego de uma maneira sustentável no médio e longo prazo" (VON STRITZKI; CABRERIZO, 2011, p. 49).

Bencke et al. (2018) também fazem referência à criação de ambientes de inovação, relacionando o papel desempenhado pelos atores da tríplice hélice. Os autores sustentam seu estudo em Etzkowitz (2009), segundo o qual a inovação tem assumido um

\footnotetext{
3 O debate teórico abordado neste texto insere-se no processo de investigação do Projeto de Pesquisa Signos Distintivos Territoriais, Indicação Geográfica e Desenvolvimento Territorial, com financiamento do CNPq (Bolsa Produtividade em Pesquisa).

${ }^{4}$ Autores referenciados em Aristizábal et al. (2018).
} 
novo significado nos últimos anos, em que o desenvolvimento de novos produtos nas empresas está relacionado à criação de novos arranjos entre as esferas institucionais que promovem as condições para inovação. A transformação e as inter-relações das esferas institucionais da academia, indústria e governo passam a moldar a dinâmica da inovação para o desenvolvimento regional e de cidades inteligentes.

O sistema de normas da Aenor ${ }^{5}$ assim define cidade inteligente ou smart city:

Cidade inteligente (Smart City) é a visão holística de uma cidade que aplica as TICs para a melhora da qualidade de vida e a acessibilidade de seus habitantes e assegura um desenvolvimento sustentável, econômico, social e ambiental em melhora permanente. Uma cidade inteligente permite aos cidadãos interatuar com ela de forma multidisciplinar e se adapta em tempo real às suas necessidades, de forma eficiente em qualidade e custos, oferecendo dados abertos, soluções e serviços orientados aos cidadãos como pessoas, para resolver os efeitos do crescimento das cidades, em âmbitos públicos e privados, através da integração inovadora de infraestruturas com sistemas de gestão inteligente.

Outros autores, como Estévez e Janowski (2016), compreendem a cidade inteligente como uma derivação da cidade digital, o que implica incorporar as TICs, por exemplo, na construção de edifícios, sistemas de transporte, escolas, espaços e serviços públicos integrados, na forma de sistemas urbanos inteligentes. Assim, quando tais inovações passam a orientar o uso da tecnologia digital como motor para o desenvolvimento na sua dimensão ambiental, social e econômica, estaremos gerando cidades inteligentes (CASTRO OBANDO, 2017).

Caragliu, Del Bo e Nijkamp (2011) afirmam que uma cidade pode ser definida como inteligente quando os investimentos em capital humano e social, assim como em infraestruturas, fomentam o desenvolvimento econômico sustentável e uma alta qualidade de vida para sua população, com um manejo inteligente dos recursos naturais por meio da ação participativa e o compromisso. Os autores, portanto, destacam cinco aspectos centrais para que se possa falar em cidades, regiões ou territórios inteligentes: (i) investimento na formação e/ou capacitação humana, da mesma forma que em infraestruturas; (ii) sistemas produtivos sustentáveis; (iii) proporcionar um alto padrão de qualidade de vida para os residentes; (iv) um manejo inteligente dos recursos naturais; e (v) práticas coletivas participativas e comprometidas.

Complementarmente, Moss Kanter e Litow (2009) resumem o conceito de cidade inteligente em três argumentos centrais: (i) é uma cidade que utiliza a tecnologia para melhorar a infraestrutura humana do mesmo modo com que pode melhorar a estrutura física; (ii) uma cidade inteligente entende que as pessoas são os conectores mais importantes de múltiplos subsistemas, convertendo a cidade de um conjunto mecânico de elementos de infraestrutura em um conjunto de comunidades humanas ativas; e (iii) cidade inteligente é a que oferece soluções sistêmicas (integradas e interconectadas) baseadas em tecnologias que podem reduzir os custos financeiros e humanos/sociais, ao mesmo tempo em que aumentam a qualidade de vida.

\footnotetext{
${ }^{5}$ Asociación Española de Normalización y Certificación/Comité Técnico de Normalización de Aenor - AEN/CTN 178 "Ciudades Inteligentes". [2015?]. Disponível em: https://www.aenor.com/.
} 
Já Batty et al. (2012) afirmam que as cidades adquirem inteligência não só pela forma com que automatizam suas funções rotineiras, mas à medida que somos capazes de monitorar, entender, analisar e planejar a cidade para melhorar a eficiência, a equidade e a qualidade de vida dos cidadãos em tempo real.

É comum relacionar-se o conceito de cidades inteligentes com o princípio da sustentabilidade. Por exemplo, para Alvarado López (2018), cidades inteligentes buscam escalar desenvolvimento econômico, social e ambiental para melhorar a qualidade de vida dos cidadãos e maior igualdade, inspiradas numa concepção inovadora pela utilização de TICs.

Aristizábal et al. (2018), considerando os diferentes sentidos atribuídos ao termo, destacam quatro formas de entender os discursos sobre cidades inteligentes: (i) cidade inteligente tecnocrática - refere-se às cidades que contam com dados e informações atualizadas que facilitam a atração de empresas, postos de trabalho, capital humano, serviços, que resultem em alta produtividade e competitividade; (ii) cidade inteligente criativa - sustenta-se nos enfoques teóricos sobre economia criativa e classe criativa, em que a tecnologia continua ocupando um papel central, que se amplia com noção de criatividade, com vistas a potenciar a diversidade da população, ressaltando aspectos sociais e humanos da cidade; ${ }^{6}$ (iii) cidade inteligente sustentável - sustenta a necessidade do uso de TICs para a melhora da sustentabilidade da cidade; e (iv) cidade inteligente participativa - ressalta os princípios da cidadania e democracia e enfatiza um entorno de inovação que capacita os cidadãos, impulsiona sua participação e envolve as empresas e os dirigentes locais na configuração de uma cidade inclusiva e participativa. $\mathrm{Na}$ realidade, os quatro tipos de discurso sobre cidade inteligente ocorrem em virtude dos diferentes objetivos e práticas desejadas pelos que o sustentam.

Saénz (2011), fazendo referência aos estudos realizados ainda na década de 70, ressalta os três pilares em que devam se sustentar as cidades inteligentes: (i) instrumentação, em que uma cidade para ser inteligente precisa sentir-se como se fosse possuir sensores que sejam capazes de recolher o máximo de informação sobre o entorno em que se vive; (ii) interconexão, com a disponibilização de uma rede de comunicação que possa suportar o movimento de toda a informação que circula no entorno; e (iii) inteligência, como a capacidade de extrair valor de toda a informação que circula no entorno, pois os dados por si de nada servem se não há um cérebro que os examine, os processe, analise os riscos, tome decisões e, finalmente, atue da melhor maneira possível para solucionar ou minimizar o impacto dos problemas.

Matus e Ramírez (2016) destacam a ideia de cidades inteligentes de acordo com os setores de atuação: setor privado, acadêmico e universitário, setor público e sociedade civil. Segundo os autores, o setor privado é mais otimista, enfatizando o uso das TICs mais avançadas como solução para gerir os recursos finitos e facilitar a interação com os cidadãos e a infraestrutura urbana. Ou seja, buscam o uso de infraestruturas de base tecnológica, desenho e aplicações digitais para o ótimo desempenho da cidade. $\mathrm{O}$ setor

\footnotetext{
${ }^{6}$ Ressalte-se que há outros enfoques que se aproximam da discussão sobre cidade inteligente, por exemplo, sobre indústria criativa, cidade criativa e territórios criativos, alguns deles fazendo relação com as atividades turísticas. Ver: Emmendoerfer e Ashton (2014). Esses enfoques teóricos não serão tratados neste texto. Já Gallas et al. (2018) realizam estudo procurando estabelecer possíveis relações entre os ativos e a inovação territorial, como forma de alavancar o desenvolvimento de cidades criativas.
} 
acadêmico e universitário é mais crítico e propositivo diante do conceito, procurando acentuar a capacidade das cidades inteligentes para inovar, gerar conhecimento e fortalecer o capital humano dos residentes a partir do uso das TICs. Este setor tem gerado conhecimentos com potencial de contribuir no planejamento urbano, passando pelas economias baseadas no conhecimento, até tecnologias de mobilidade. O setor público, como intermediário entre os demais setores e a cidadania, busca resolver os problemas do urbanismo mediante avanços na interconectividade, para melhoria (i) na mobilidade e infraestrutura de transporte, (ii) no fluxo de capitais, investimentos e transações que mantenham o fluxo da economia local e nacional e (iii) para facilitar a interação e cooperação com os demais atores do sistema internacional. Já a sociedade civil, beneficiada e/ou impactada pelo novo processo de urbanização, espera que o uso das TICs favoreça a otimização dos serviços urbanos (mobilidade, atenção sanitária, educação, segurança...), sempre e quando possa acessar tais tecnologias e adquirir as habilidades digitais necessárias para interatuar com o ambiente tecnificado. Caso contrário, as pessoas correm o risco de permanecer excluídos dos benefícios apregoados por este novo paradigma urbano.

Para Jiménez Herrero (2016, p. 128),

Uma cidade inteligente é aquela que mediante a colocação em prática de uma rede de iniciativas e programas inter-relacionados de atuação e controle, suportados por tecnologias inovadoras, uma gestão sustentável da matéria e da energia, e uma mudança de comportamentos, potencia o desenvolvimento econômico e social de seus habitantes de forma sustentável, ou seja, sem comprometer o bem-estar das gerações futuras.

Uma cidade inteligente, portanto, permite aos cidadãos interatuar com o meio de forma interdisciplinar, e este adapta-se no tempo real às suas necessidades, de forma eficiente em qualidade e custos, oferecendo dados abertos, soluções e serviços orientados aos cidadãos como pessoas, não números, por meio da integração inovadora entre infraestruturas e sistema de gestão inteligente (JIMÉNEZ HERRERO, 2016). Esta é uma tendência que poderia ser chamada de "emparelhar humanos e máquinas", tratada pela OCDE, em relação à inovação no setor público (EMMENDOERFER, 2019b).

No longo prazo, a única opção que tem sentido é procurar alcançar a sustentabilidade integral do sistema socioecológico, como um sistema formado por um componente societal em interação com um componente ecológico e que pode se definir em diferentes escalas, desde o local ao global, tal como pode ser na escala urbana ou rural. Esta perspectiva é compatível com a ideia de sustentabilidade forte, na medida em que os distintos tipos de capital não são necessária nem totalmente substituíveis, especialmente o capital natural, ${ }^{7}$ na medida em que existem componentes ambientais únicos e alguns processos ambientais podem ser irreversíveis (JIMÉNEZ HERRERO, 2016).

Assim, visto a necessidade de superação das concepções confusas de sustentabilidade, atualmente assume-se a sustentabilidade em termos de "resiliência ecológica", como a propriedade e o fundamento dos sistemas socioecológicos com capacidade de

Dallabrida (2020c), seguindo concepções teóricas da Escola Territorialista Italiana de Geografia, entende ser mais adequado substituir o termo capital por patrimônio, em que os tipos de capital são os componentes do patrimônio territorial. 
auto-organização, autorregeneração e adaptação para enfrentar e amortizar as perturbações e manter seus atributos essenciais. "Esta maneira de interpretar os processos sustentáveis na dimensão urbana e territorial implica avanços inovadores nos sistemas de governança e gestão das cidades e regiões" (JIMÉNEZ HERRERO, 2016, p. 110), na perspectiva de engendrar cidades ou territórios saudáveis, economicamente eficientes e socialmente inclusivos. ${ }^{8}$

É recorrente associar a concepção de cidade inteligente com a de sustentabilidade. Trata-se de adotar soluções inteligentes que favoreçam a sustentabilidade da cidade ou território, assim como criar novas oportunidades de investimento que atraiam novas indústrias, com postura e comportamento diferenciado do que é usual, superando o propósito único da lucratividade com menor custo, o que implica redução do uso de mão de obra e consumo indiscriminado de recursos naturais. Independente da estratégia a ser concebida para gerar cidades inteligentes, as TICs, apesar de imprescindíveis, devem estar a serviço dos avanços pretendidos, não com um fim em si mesmas. Cidades inteligentes, portanto, são consideradas aquelas que desenvolvem iniciativas de excelência para dar resposta às necessidades da pessoa humana, inspiradas numa concepção inovadora mediante a utilização de TICs.

O Quadro 1 é uma tentativa de síntese das principais concepções sobre cidades inteligentes ou smart cities.

Quadro 1 - Síntese das principais concepções sobre cidade inteligente ou smart cities

\begin{tabular}{|l|l|}
\hline Referência & \multicolumn{1}{c|}{ Síntese da concepção } \\
\hline AENOR, & $\begin{array}{l}\text { Cidade concebida a partir de uma visão holística que aplica as TICs para a } \\
\text { melhora da qualidade de vida e a acessibilidade de seus habitantes e assegura } \\
\text { um desenvolvimento sustentável, econômico, social e ambiental, em melhora } \\
\text { permanente. }\end{array}$ \\
\hline MOSS KANTER; & $\begin{array}{l}\text { Cidade que utiliza a tecnologia para melhorar a infraestrutura humana e física, } \\
\text { onde se entende que as pessoas são os conectores mais importantes de múltiplos } \\
\text { subsistemas e que oferece soluções sistêmicas (integradas e interconectadas), } \\
\text { baseadas em tecnologias que podem reduzir os custos financeiros e humanos/sociais, } \\
\text { com aumento da qualidade de vida. }\end{array}$ \\
\hline $\begin{array}{l}\text { CARAGLIU; DEL } \\
\text { BO; NIJKAMP } \\
\text { (2011) }\end{array}$ & $\begin{array}{l}\text { Cidade em que os investimentos em capital humano e social, assim como em } \\
\text { infraestruturas, fomentam o desenvolvimento econômico sustentável e uma alta } \\
\text { qualidade de vida para sua população, com um manejo inteligente dos recursos } \\
\text { naturais, por meio da ação participativa e o compromisso. }\end{array}$ \\
\hline SAÉNZ (2011) & $\begin{array}{l}\text { Ressalta os três pilares em que devam se sustentar as cidades inteligentes: (i) } \\
\text { instrumentação, com o máximo de informação sobre o entorno em que se vive; } \\
\text { (ii) interconexão, com a disponibilização de uma rede de comunicação que possa } \\
\text { suportar o movimento de toda a informação que circula no entorno; (iii) inteligência, } \\
\text { como a capacidade de extrair valor de toda a informação que circula no entorno, } \\
\text { como um “cérebro" que analise os dados, os processe, avalie os riscos e tome as } \\
\text { decisões capazes de solucionar ou minimizar o impacto dos problemas. }\end{array}$ \\
\hline $\begin{array}{l}\text { VON STRITZKI; } \\
\text { CABRERIZO } \\
\text { (2011) }\end{array}$ & $\begin{array}{l}\text { Cidade como ambientes territoriais forjados por núcleos de inovação e criatividade } \\
\text { que favoreçam o crescimento econômico e a criação de emprego de uma maneira } \\
\text { sustentável. }\end{array}$ \\
\hline
\end{tabular}

\footnotetext{
${ }^{8}$ Sobre cidades inteligentes, além das publicações referidas, destacam-se as seguintes: Zanella et al. (2014), DíazDíaz, Muñoz e Pérez-González (2017), Hajduk (2016), Cunha et al. (2016), Rassia e Pardalos (2017), Mora, Bolici e Deakin (2017), Alves, Dias e Seixas (2019), Seixas (2019), Finquelievich et al. (2019). São sugestões de leituras para o aprofundamento do tema.
} 


\begin{tabular}{|c|c|}
\hline $\begin{array}{l}\text { BATTY et al. } \\
(2012)\end{array}$ & $\begin{array}{l}\text { Cidade que não só automatiza suas funções rotineiras, senão que seja capaz de } \\
\text { monitorar, entender, analisar e planejar a cidade para melhorar a eficiência, a } \\
\text { equidade e a qualidade de vida dos cidadãos em tempo real. }\end{array}$ \\
\hline $\begin{array}{l}\text { SUJATA; } \\
\text { SAKSCHAM; } \\
\text { TANVI, } 2016\end{array}$ & $\begin{array}{l}\text { Concepção geral: cidades que integram as mais diferentes tecnologias de informação } \\
\text { e comunicação (TICs), com o fim de torná-las mais eficientes, sustentáveis e } \\
\text { habitáveis. }\end{array}$ \\
\hline $\begin{array}{l}\text { JIMÉNEZ } \\
\text { HERRERO } \\
(2016)\end{array}$ & $\begin{array}{l}\text { Cidade que se mova mediante uma rede de iniciativas e programas inter-relacionados } \\
\text { de atuação e controle, suportados por tecnologias inovadoras, uma gestão sustentável } \\
\text { da matéria e da energia, uma mudança de comportamentos, capazes de engendrar } \\
\text { soluções inteligentes que favoreçam a sustentabilidade da cidade ou território, } \\
\text { capazes de criar novas oportunidades de investimento, que atraiam novas indústrias, } \\
\text { e não resuma suas iniciativas ao propósito da lucratividade com menor custo, o que } \\
\text { implica na redução do uso de mão de obra e consumo indiscriminado de recursos } \\
\text { naturais. }\end{array}$ \\
\hline $\begin{array}{l}\text { MATUS; } \\
\text { RAMÍREZ } \\
(2016)\end{array}$ & $\begin{array}{l}\text { Destacam a concepção dominante, de acordo com os setores: (i) privado, mais } \\
\text { otimista, ressalta o uso de infraestruturas de base tecnológica, desenho e aplicações } \\
\text { digitais para o ótimo desempenho da cidade; (ii) acadêmico, visão crítica e } \\
\text { propositiva, acentuando a capacidade das cidades inteligentes para inovar, gerar } \\
\text { conhecimento e fortalecer o capital humano dos residentes, a partir do uso das } \\
\text { TICs; (iii) setor público, como intermediário entre os demais setores e a cidadania, } \\
\text { busca resolver os problemas do urbanismo, mediante avanços na interconectividade, } \\
\text { para melhoria na mobilidade, infraestrutura de transporte, no fluxo de capitais, } \\
\text { investimentos e transações e para facilitar a interação e cooperação com os demais } \\
\text { atores do sistema internacional; (iv) sociedade civil, espera que o uso das TICs } \\
\text { favoreça a otimização dos serviços urbanos (mobilidade, atenção sanitária, educação, } \\
\text { segurança...), facilite o acesso de tais tecnologias e as pessoas sejam capazes de } \\
\text { adquirir as habilidades digitais necessárias para interatuar com o ambiente, de forma } \\
\text { inclusiva. }\end{array}$ \\
\hline $\begin{array}{l}\text { CASTRO } \\
\text { OBANDO } \\
(2017)\end{array}$ & $\begin{array}{l}\text { Cidade onde as inovações passam a orientar o uso da tecnologia digital, como motor } \\
\text { para o desenvolvimento, na sua dimensão ambiental, social e econômica, em que as } \\
\text { TICs, apesar de imprescindíveis, estejam a serviço dos avanços pretendidos, não um } \\
\text { fim em si mesmas. }\end{array}$ \\
\hline $\begin{array}{l}\text { ALVARADO } \\
\text { LÓPEZ (2018) }\end{array}$ & $\begin{array}{l}\text { Cidade que busque o desenvolvimento econômico, social e ambiental para melhorar } \\
\text { a qualidade de vida da cidadania e maior igualdade, inspiradas numa concepção } \\
\text { inovadora, pela utilização de TICs. }\end{array}$ \\
\hline $\begin{array}{l}\text { ARISTIZÁBAL et } \\
\text { al. (2018) }\end{array}$ & $\begin{array}{l}\text { Ressalta aspectos presentes nas cidades inteligentes, em razão dos diferentes } \\
\text { objetivos e práticas desejados pelos articuladores: (i) tecnocrática, cidades que } \\
\text { contem com dados e informações atualizadas, que facilitam a atração de empresas, } \\
\text { postos de trabalho, capital humano, serviços, que resultem em alta produtividade } \\
\text { e competitividade; (ii) criativa, além dos aspectos técnicos, ressaltam a noção de } \\
\text { criatividade, com vistas a potenciar a diversidade da população; (iii) participativa, } \\
\text { como um entorno de inovação que impulsiona a participação cidadã e envolve as } \\
\text { empresas e os dirigentes locais na configuração de uma cidade inclusiva e plural. }\end{array}$ \\
\hline $\begin{array}{l}\text { NASCIMENTO; } \\
\text { SOUZA; } \\
\text { SERRALVO } \\
\text { (2019) }\end{array}$ & $\begin{array}{l}\text { Cidade inteligente, como ambiente mais adequado para melhorar a qualidade de vida } \\
\text { e a competitividade dos habitantes das cidades, mediante uma gestão inteligente do } \\
\text { espaço urbano, por autoridades municipais, cidadãos e representantes da indústria de } \\
\text { novas tecnologias. }\end{array}$ \\
\hline
\end{tabular}

Fonte: Elaboração própria (2020).

A intensificação da difusão e do uso das TICs permite referir-se à chamada internet das coisas, tema abordado de forma sucinta na sequência. 


\section{DAS CIDADES INTELIGENTES À INTERNET DAS COISAS}

O termo internet das coisas, tradução da língua inglesa de Internet of Things (IOT), origina-se dos fundadores do Auto-ID Center (ASHTON, 2009; BROCK, 2001 apud SANTUCCI, 2010), posto que o termo auto-ID se refere às tecnologias de identificação utilizadas para automatizar, reduzir erros e aumentar a eficiência nas indústrias, incluindo os códigos de barras, cartões inteligentes, sensores, reconhecimento de voz e biometria.

Segundo Santucci (2010), é a partir de 2005 que o conceito de internet das coisas ganhou destaque, mediante publicação da União Internacional de Telecomunicações. Na sequência, a partir de uma abordagem mais holística, afirmando que a loT irá conectar os objetos de forma sensorial e inteligente, é que se combinou tecnologicamente sensores, redes sem fio e nanotecnologia.

Assim, graças à possibilidade de conexão dos mundos físico e virtual, são possíveis mudanças constantes, ativando novas formas de comunicação entre pessoas e coisas e entre as coisas (NASCIMENTO; SOUZA; SERRALVO, 2019), ${ }^{9}$ permitindo que objetos ao nosso redor estejam conectados à internet e comuniquem-se com a menor intervenção humana possível (DE MATOS; AMARAL; HESSEL, 2017).

$\mathrm{Na}$ medida em que for possível conectar tudo à Internet, o avanço seguinte é a Internet of Everything ( $\mathrm{loE}$ ), a internet de todas as coisas, com possibilidade de conectar pessoas, processos, dados e coisas. A loE inclui várias transições tecnológicas, incluindo a IoT. Com a operacionalização da loE, pessoas, coisas e serviços poderão interagir de forma autônoma. Para tal, alguns desafios apresentam-se ainda: (i) necessidade de uma conectividade robusta; (ii) necessidade de avançar em termos de segurança no manuseio de dados e informações; (iii) superar o desafio de operacionalizar um alto volume, variedade e velocidade na circulação dos dados e informações; (iv) outros, não relacionados com questões técnicas e, sim, de governança, de gestão de dados e modelos de negócio que favoreçam toda a sociedade. ${ }^{10}$

Kim (2016) destaca que a adoção de tecnologia relacionada à internet das coisas de parte das empresas, vem ganhando importância cada vez maior recentemente. $\mathrm{O}$ autor ressalta que a adoção dessa tecnologia decorre de pressões tecnológicas, sociais e competitivas que as impulsionaram a inovar e transformar. Tecnologias, por exemplo, do tipo big data e business analytics, com seus sensores incorporados, ou referentes à inteligência artificial, robótica e diferentes formas de automação, capturam grandes quantidades de dados e os transmitem para ferramentas business intelligence e analytics, permitindo resolver problemas de negócios e fornecer serviços de valor agregado aos clientes.

\footnotetext{
${ }^{9}$ Para um aprofundamento do tema cidades inteligentes e internet das coisas, recomenda-se esta publicação. Dentre as outras publicações referenciais, destacam-se Batalla et al. (2017), reunindo um grupo especializado de autores abordando diferentes aspectos do tema.

${ }^{10}$ Informações resumidas de: https://blogbrasil.comstor.com/bid/401306/10-desafios-a-serem-resolvidos-sobre-aIoE. Acesso em: 4 mar. 2020.
} 
O que se convencionou chamar de internet das coisas (IOT) ou internet de todas as coisas (IoE), portanto, são sistemas tecnológicos que favorecem a inovação nos diferentes âmbitos espaciais, servindo como infraestruturas indispensáveis tanto para as administrações públicas quanto para empresas e cidadãos.

\section{VISÕES CRÍTICAS SOBRE SMART CITY OU CIDADES INTELIGENTES}

Apesar de boa parte dos debates teóricos sobre cidades inteligentes apontarem para novas perspectivas, como uma estratégia vital para a melhoria da qualidade de vida para empresas, pessoas e comunidades, na medida em que os cidadãos se beneficiam com o bem-estar proporcionado pelas altas tecnologias, logística, produção de energia, dentre outros fatores (DAMERI, 2013; COCCHIA, 2014), outros autores, como Komninos (2011), argumentam que as soluções inteligentes adotadas tiveram impactos limitados na competitividade, no emprego e na sustentabilidade das cidades. Argumenta ainda o autor, que as cidades inteligentes ainda não têm soluções para os grandes problemas urbanos, e que as soluções, em geral, ocorrem em razão do avanço da tecnologia e não para responder demandas e necessidades reais.

Referindo-se aos desafios, Angelidou (2014) complementa, acrescentando que o planejamento estratégico para cidades inteligentes ainda é uma ideia abstrata, sendo pouco explorado, existindo interesses conflitantes de parte dos governos locais, instituições de pesquisa e provedores de tecnologia, além de ser influenciado pelas forças do mercado, resultando em diferentes decisões e resultados. Já para Albino, Berardi e Dangelico (2015), as cidades devem encontrar formas de gerenciar novos desafios, como algumas que buscam soluções com efeitos positivos a longo prazo na economia. Na mesma linha de raciocínio, Komninos (2011) afirma que a pesquisa deve enfocar mais as arquiteturas de integração entre os aspectos digitais e físicos das cidades, pois a necessidade de soluções que ligam o espaço físico e os elementos digitais das cidades é muito mais significativa do que a demanda por aplicativos independentes e soluções digitais.

Ou seja, criar soluções integradas é a chave para uma maior inteligência espacial em cidades inteligentes, pois a cidade contemporânea não é apenas uma estrutura física, sendo também uma vasta rede de tecnologias modernas com o objetivo de otimizar o consumo dos recursos e processos para prevenir efeitos adversos resultantes de seu funcionamento (NASCIMENTO; SOUZA; SERRALVO, 2019).

O aspecto inquestionável em relação às cidades inteligentes é que sua estruturação exige esforços baseados na inovação. Se, no entanto, é verdade que a revolução tecnológica por meio das TICs é um fato, não se pode afirmar que a totalidade dos lugares, sociedades ou cidades tenha sido beneficiada adequadamente por tais tecnologias. Isso deve-se ao fato de que os processos de inovação e mudanças técnicas, historicamente e em geral, assumem um comportamento excludente, localizando-se, em grande medida, em algumas regiões, países ou setores produtivos. Isso resulta na exigência de que os benefícios se propaguem para regiões, países e, também, aos setores da população menos favorecidos, pois só assim a inovação contribui para garantir maior igualdade social, um meio ambiente saudável, acesso à educação e saúde de qualidade (ALVARADO 
LÓPEZ, 2018). Não é o que mais se percebe em regiões ou países periféricos, política ou economicamente. Reafirma Guallart (2012, p. 23): "A internet tem mudado nossas vidas, no entanto não tem transformado nossas cidades".

Ainda, dentre as posições críticas, a principal é que muitas das prerrogativas atribuídas às cidades inteligentes não são replicáveis, pois, em geral, partem da ideia de construção de uma nova cidade, repleta de tecnologias ou de novos sistemas de TICs, no entanto esquecem do que existe ou está instituído, além da conveniência de complementação ou avanços no que já existe. Muitas das propostas tratam de incutir em nossas mentes "imagens mentais de utopias urbanas" (ARES; CID, 2012).

Outro autor que faz uma crítica às abordagens sobre smart city é Hollands (2008). O autor aponta vários aspectos: (i) o conceito carece de uma definição precisa, utilizando diferentes sinônimos, mesmo que não sejam intercambiáveis (inteligente, criativa, digital, conectada, cultural); (ii) o conceito é utilizado com fins de marketing e raramente refere-se a mudanças nas infraestruturas e políticas urbanas; (iii) o conceito é assumido de forma acrítica, como se as cidades inteligentes necessariamente impactem no desenvolvimento urbano; (iv) o conceito implica contradições ideológicas, pois, por exemplo, se diz que leva em conta o cidadão, no entanto impõe uma agenda; (v) os usuários do conceito aceitam acriticamente o que se propõe para as cidades inteligentes como necessariamente adequado em si mesmo; (vi) o conceito tem-se convertido num mantra, no qual se considera que as TICs são equivalentes à regeneração urbana; e (vii) há uma ênfase excessiva em relação a que o desenvolvimento urbano é impulsionado por negócios privados em aliança com governos e sociedade, como um novo modelo de governança para manter os investimentos do capital financeiro, como um modelo neoliberal, mais centrado nas empresas do que nos cidadãos (HOLLANDS, 2008, p. 307-308).

Neste ínterim, Schiavo e Gelfuso (2018) lembram que o neoliberalismo não se impõe de forma homogênea, com distintas formas de intervenção, estando presente nos debates sobre cidades inteligentes por meio de organismos internacionais e empresas do setor privado, difundindo normas, estratégias e/ou procedimentos que, rapidamente, são adotados pelos governos locais mediante políticas públicas. Mesmo que alguns governos progressistas assumam discursos e práticas que privilegiem os princípios do "direito à cidade", predominam nas cidades latino-americanas modos operacionais do chamado "urbanismo de mercado". Salientam os autores que, na lógica operacional pública ou privada, permanece a confusão sobre como passar das soluções isoladas e desconectadas à criação de sistemas mais integrados, inclusivos e participativos.

Na mesma linha de discussão sobre o urbanismo de mercado, Sánchez Chillón (2017) alerta para o fato de que o debate sobre cidades inteligentes está sendo utilizado como instrumento narrativo para a consolidação de um "novo poder urbano universal", utilizando vetores narrativos como cidades inovadoras, empreendedoras, resilientes, inteligentes e sustentáveis, ocultando, sob várias capas de maquiagem tecnológica e impostura digital, territórios subjugados pelo império do artefato, na forma de uma nova ditadura contemporânea. ${ }^{11}$ Neste sentido, sustenta o autor que o urbanismo de

${ }^{11}$ Veja-se também sobre o tema: Peck (2002), Peck e Theodore (2015). 
qualidade, a otimização dos usos do espaço urbano e sua reversibilidade adaptativa, a morfologia funcional dos espaços públicos e sua beleza, enfim, o bom planejamento territorial e suas capacidades de interação com a cidadania cada vez mais interconectada, deixou de ocupar lugar preferencial na agenda da política municipal ou nos planos estratégicos dos municípios ou regiões. Segundo o autor, parece que em muitos lugares o urbanismo cumpre sua função apenas de mero provedor massivo de recursos imobiliários, submetido exclusivamente às leis do mercado especulativo, o qual tem se revelado, não poucas vezes, nefasto para nossas cidades.

Como reafirmação desta posição, Feldman e Girolimo (2018) afirmam que o empresarialismo urbano tem incorporado de forma ativa e protagonista o paradigma tecno-centrista de gestão urbana, via projetos de smart cities, como projeto hegemônico da cidade e como mecanismo de dominação do ordenamento territorial. O contexto que facilitou ações de caráter empresarialista se originou ainda na década de 70 do século 20 , quando emergiu um consenso de que as cidades deviam adotar uma atitude empresarial ante o desenvolvimento econômico, transcendendo as fronteiras nacionais, passando a ser assumido tal entendimento por partidos políticos e governantes. A débil capacidade estatal para controlar fluxos multinacionais de dinheiro estimulou que os governantes locais buscassem desencadear novas estratégias para tornar atrativo o espaço local, com fins de atrair capitais ou investimentos. Em grande medida, problemas que hoje estão presentes na maioria das cidades, em especial nos países ditos subdesenvolvidos ou emergentes, resultaram do avanço do empresarialismo urbano (desindustrialização, gentrificação e periferização das populações de baixa renda, violência urbana, especulação imobiliária...). ${ }^{12}$

Fernández González (2016) faz uma densa revisão do discurso subjacente nas visões predominantes sobre smart cities, apresentando-o como um imaginário tecnológico generalizado na agenda das políticas urbanas, apontando uma série de mitos: (i) 0 mito da eficiência operativa, considerando a obsessão pela otimização como único fim nos serviços urbanos; (ii) o mito da sustentabilidade, referindo-se a uma sustentabilidade débil baseada na irresponsabilidade dos comportamentos; (iii) o mito da competitividade, tendo a acumulação tecnológica como fator de desenvolvimento econômico; (iv) o mito da integração, como aspiração a um sistema de gestão e controle perfeitamente integrado e uma experiência sem friç̧ões; ( $v$ ) o mito da simplificação, aspirando a redução da complexidade aos modelos de simulação, no lugar de pensar a cidade como problema; (vi) o mito da neutralidade do dado, a ficção de um conhecimento asséptico, sem riscos, perfeito e objetivo; (vii) o mito da despolitização, a aspiração de conseguir, mediante mais informação, um horizonte pós-político de gestão urbana; (viii) o mito da suficiência tecnológica, com a identificação da tecnologia como elemento crítico em qualquer questão relacionada com a cidade e, por fim, (ix) o mito da desejabilidade intrínseca, apresentando o progresso tecnológico como inevitável e inquestionável, ou seja, a ideia de que "O futuro da cidade será necessariamente inteligente e as tecnologias associadas são sistematicamente apresentadas como progressos que cedo ou tarde se instalarão na paisagem urbana" (FERNÁNDEZ GONZÁLES, 2016, p. 55).

\footnotetext{
${ }^{12}$ Por restrições de espaço, deixa-se de mencionar mais publicações sobre empresarialismo e gentrificação urbana. Por exemplo: Meethan (1996), Leite (2007) e Zukin (2010).
} 
Para Feldman e Girolimo (2018), os impactos nefastos do empresarialismo urbano podem ser dirimidos em dois campos interconectados: (i) o campo político, associado aos governos locais, o que implica em discutir a orientação geral do projeto de cidade, as dinâmicas de inclusão/exclusão, os recursos, ferramentas e capacidades que estão em jogo no processo de gestão urbana; (ii) o campo simbólico, vinculado à definição do papel da tecnologia na sociedade, isto é, a construção de consensos em torno de que problemáticas podem ser abordadas com êxito, quais são suas principais contribuições na gestão urbana, quais são suas limitações, que tensões emergem de seu uso, que atores envolve em sua produção, planejamento e aplicação, e como se incorporar o conhecimento local na abordagem das problemáticas territoriais.

$\mathrm{Na}$ perspectiva de superar as visões críticas, Hollands (2008, p. 315) apresenta propostas, como: (i) que as cidades inteligentes devem iniciar por considerar com seriedade as pessoas e o capital humano, seus conhecimentos e habilidades e não a tecnologia em si mesma; (ii) deve-se equilibrar o poder entre o uso das TICs e os negócios, o governo e as pessoas atingidas, entre crescimento econômico e sustentabilidade; (iii) as cidades reais devem fazer uso das TICS de forma que permita emergir uma "cultura pública virtual", em que o interesse público se sobreponha ao privado; (iv) tornar uma cidade plural, levando a sério a diversidade cultural e social; (v) promover a igualdade de gênero; e (vi) aproveitar o talento e a criatividade dos jovens. ${ }^{13}$

Ainda como proposições, Sánchez Chillón (2017) defende a emergência de um novo paradigma de "Diplomacia de Cidades" no marco de uma arena internacional elástica, complexa e físico-digital, mediante o compartilhamento de diagnósticos sobre os problemas de natureza universal que se manifestam nos entornos urbanos (exemplo: reflexos do câmbio climático), sob a forma de uma nova alocução sobre a capacidade e ativos das cidades para afrontá-los. Assim sendo, tendo como base estratégias de inovação e resiliência, deve-se instituir um novo "poder urbano", sustentado na distribuição do poder aos governos municipais, mediante a condição de que os mesmos desenvolvam habilidades para fixar "agendas de governo", além de confrontar a narrativa política global ${ }^{14}$.

É incontestável que o século 21 será o século das cidades, reafirmando-se como centro da atividade social, administrativa e econômica. Como consequência, neste contexto os países ou estado-nação vêm perdendo poder em detrimento das cidades. 0 foco na cidade, apesar de parecer lógico, por ser onde se manifestam os principais problemas, oferece o risco, como adverte Sánchez Chillón (2017), de maior ingerência dos agentes do mercado especulativo, o que exige do poder público local direcionar esforços para adotar uma gestão mais inteligente, sustentada nos princípios da sustentabilidade, transparência e respeito aos interesses de todos seus cidadãos.

Turok (2009), contudo, defende que a ação do poder público local não se torne uma armadilha, uma ação fugaz e de natureza estritamente política para a própria cidade. Nesse sentido, para o autor, é fundamental que o processo de inovação seja endó-

\footnotetext{
${ }^{13}$ Emmendoerfer et al. (2016) relatam um estudo de caso, apresentando mais contribuições sobre o tema.

${ }^{14}$ Neste sentido, o autor cita exemplos no Reino Unido.
} 
geno e colaborativo, envolvendo diferentes agentes públicos e privados e priorizando insumos autóctones da região. Outra advertência do autor é que as ações de marketing público se direcionem ao propósito de tornar uma cidade distinta das demais.

As limitações e desafios ainda não enfrentados nos contextos urbano e rural, em que as abordagens sobre cidades inteligentes não contribuem adequadamente, exigem avanços, tanto no enfoque teórico quanto nos aspectos operacionais. É sobre o que se pretende refletir na sequência do texto.

\section{DA CIDADE INTELIGENTE AO TERRITÓRIO INOVADOR PARA A INTELIGÊNCIA TERRITORIAL}

No decorrer do texto foram sintetizadas contribuições teóricas sobre smart city ou cidade inteligente, referindo-se ainda à internet das coisas, com base em diferentes autores, inclusive com posturas críticas. Complementa-se essa discussão teórica com um conceito que, por vezes, é considerado sinônimo de cidade inteligente, no entanto tem sua distinção: o de território inovador ou inteligente.

O debate teórico, que resultou na concepção de território inovador, origina-se na chamada Economia do Conhecimento, transladada ao plano territorial com conceitos, tais como de região ou territórios inteligentes, learning region ou territórios que aprendem (FLORIDA, 1995; ANTONELLI; FERRÃO, 2001), todos sustentados na ideia de protagonismo do conhecimento e da aprendizagem coletiva como recursos específicos. Foram importantes, também, contribuições teóricas sobre sistemas nacionais e regionais de inovação (LUNDVALL; JOHNSON, 1994; COOKE; MORGAN, 1998), que propõem uma visão integrada dos processos inovadores, em que participam atores diversos, desde os que produzem conhecimento e o transmitem até os que o utilizam, junto com instituições e infraestruturas existentes no meio.

Outra contribuição importante é sobre Milieux Innovateurs (meios ou entornos inovadores), a partir de estudos realizados no Groupe de Recherche sur les Millieux Innovateurs (GREMI), liderados inicialmente por Aydalot (1986), depois envolvendo outros pesquisadores, tais como Crevoisier (1993), Camagni (1995) e Maillat (1995). Tais estudos partiam da hipótese de que o sucesso nas trajetórias de desenvolvimento de certas regiões resulta de suas capacidades intrínsecas de fabricar novos produtos, adotar novos processos produtivos, bem como assumir configurações organizacionais e institucionais inovadoras (CREVOISIER, 1993). Assim, a empresa não seria o agente inovador isolado, passando a ser parte do meio que a faz agir. Os comportamentos inovadores, portanto, não seriam nacionais, mas territoriais, e o que caracterizaria os meios inovadores não seria a dotação de atributos naturais ou de localização, mas, sobretudo, a densidade do seu tecido social, ou do seu capital relacional (MAILLAT, 1995).

Para introduzir o tema, afirma-se ter total concordância com a tese de Covas e Covas (2019, p. 43), de que "[...] todos os territórios têm uma inteligência coletiva tácita ou implícita que os seus principais atores e representantes podem explicitar e desenvolver se forem capazes de resolver os seus principais déficits de conhecimento". Esse desafio, segundo os autores, implica na transição das tecnologias de informação e conhecimento para os territórios inteligentes, exigindo da sociedade local uma atuação orgânica de criação e enraizamento territorial. "Estamos, portanto, perante um problema de escolhas e opções, logo, de atores-rede e modelos de governança territorial que 
fazem apelo à arte e ciência das redes sociais". O grande desafio, para os autores, é a qualidade do capital social, isto é, a emergência de um ator-rede que seja capaz de conciliar "ordem com inteligência e imaginação", em benefício dos territórios e, sobretudo, dos mais desfavorecidos. ${ }^{15}$

A literatura, em geral, utiliza os termos território inteligente e território inovador com o mesmo sentido. Komninos (2008) refere-se aos sistemas inteligentes e globais como produto da evolução dos sistemas de inovação que, segundo o autor, refletem o conceito de território inteligente. Assim sendo, os territórios inteligentes resultam da interseção de duas grandes esferas: (i) o sistema de inovação caracterizando o conjunto variado de capacidades, instituições, organizações, empresas, agentes de conhecimento, capital humano e intelectual; (ii) a reconstrução digital da cidade e os espaços digitais colaborativos de inovação e gestão do conhecimento.

Desde a perspectiva geográfica, não apenas desde uma ótica econômico-empresarial, um território inovador, para Méndez (2002), deverá incluir: (i) a criação de um determinado clima social, onde é perceptível a mobilização em favor do desenvolvimento local e uma permeabilidade à incorporação de novidades capazes de romper inércias herdadas, no momento, ineficientes ou injustas; (ii) a existência de redes locais de cooperação que tornem possível a realização de projetos inovadores, coletivamente assumidos; (iii) a presença de instituições públicas, locais e regionais, que adotem uma atitude protagonista em apoio à inovação e ao desenvolvimento territorial, mediante iniciativas negociadas por atores das diferentes instâncias da sociedade local, de forma participativa e colaborativa; (iv) um esforço na melhora da formação dos recursos humanos, com a requalificação de empresários e trabalhadores, adequando a oferta formativa às demandas e ao saber fazer local.

Um território inovador conta com as capacidades para a obtenção, organização e transformação sistêmica de dados e informação em um conhecimento diferencial e em uma inteligência coletiva que se refletem na cultura e na interação social para a tomada de decisões, a construção de soluções e a produção e entrega sistêmica de propostas de valor. Isto implica que se leve adiante um processo de apropriação regional do conhecimento (GUSMÁN, 2013).

Para Gusmán (2013, p. 78), dados transformam-se em informações se agregarmos conteúdo semântico, significação. Depois vem a transformação da informação em conhecimento, processo que se sustenta no conhecimento acumulado e na experiência, assim como nos valores e crenças.

O conhecimento é informação incorporada em atores ou agentes regionais que a utilizam ativamente na tomada de decisões e resolução de problemas. Ocorre um processo de aprendizagem nesta transformação.

\footnotetext{
$\overline{{ }^{15} \mathrm{~A} \text { discussão inicial }}$ dos autores sobre inteligência territorial é feita em diferentes publicações anteriores, uma delas no Brasil: Covas e Covas (2014).
} 
Esse mesmo processo pode ser usado para explicar a apropriação territorial de conhecimento e o desenvolvimento de uma inteligência coletiva, integrada não somente por aspectos puramente técnicos ou econômicos, mensuráveis, visíveis ou tangíveis (conhecimento explícito), senão também por elementos sociais e culturais (GUSMÁN, 2013, p. 78).

Com sentido assemelhado ao de inteligência coletiva, Farinós (2011) lembra a inteligência territorial ao fazer referência ao planejamento territorial. ${ }^{16}$ Para o autor, processos que se propõem ao planejamento do território representam um espaço de oportunidade para ensaiar e desencadear novos constructos, enfoques e métodos, na perspectiva da mediação, negociação e contratualização de estratégias territoriais de desenvolvimento entre distintos atores. Segundo o autor, estas novas práticas, as quais se referem ao exercício da governança territorial, ${ }^{17}$ sustentam-se na inteligência territorial como uma nova forma de compreender os processos territoriais, produtivos e sociais, de integrar atores e suas perspectivas, visões e iniciativas.

Conforme Girardot (2004), inteligência territorial diz respeito ao conhecimento multidisciplinar que pode melhorar a compreensão e a estrutura dinâmica dos territórios. Em outra obra, Girardot (2010, p. 26) ${ }^{18}$ define inteligência territorial como "[...] um meio para os investigadores, para os atores e para a comunidade territorial de adquirir um maior conhecimento do território, no entanto também de controlar melhor seu desenvolvimento...".

É neste mesmo sentido que Farinós (2008a) considera a inteligência territorial uma condição para a governança territorial, com vistas à elaboração de uma visão territorial compartilhada, sustentada na identificação e valorização do capital territorial. ${ }^{19}$ Refere-se à inteligência territorial como um suficiente nível de conhecimento disponível entre os atores implicados no desenvolvimento territorial, tal seja, conhecimento do sistema territorial e as formas como operam as instituições, capaz de tornar-se um marco comum de referência que permita a cooperação entre os atores territoriais.

Em outra publicação, Farinós (2011, p. 46), com base nos documentos da Enti, ${ }^{20}$ define inteligência territorial como

[...] o conhecimento necessário para compreender as estruturas do sistema territorial e suas dinâmicas, assim como o conjunto de instrumentos empregados pelos atores públicos e privados para produzir, utilizar e compartilhar este conhecimento em favor do desenvolvimento territorial sustentável. Desde esta perspectiva a inteligência territorial é uma ferramenta para a governança territorial e a participação a força motriz da mesma.

\footnotetext{
${ }^{16}$ Publicação recente refere-se a uma nova inteligência territorial na Comunidade Valenciana: Farinós e SánchezManjavacas (2019).

${ }^{17}$ Para compreensão do tema governança territorial, sugerem-se duas obras: Dallabrida (2015) e Farinós (2008b).

${ }^{18}$ Para um aprofundamento da discussão teórica sobre inteligência territorial e sua prática na Europa e América Latina, sugere-se uma publicação referencial: Bozzano et al. (2012).

${ }^{19}$ Termo que, em Dallabrida (2020a, 2020b, 2020c), é substituído por patrimônio territorial.

${ }^{20}$ European Network of Territorial Intelligence.
} 
A governança territorial faz referência a uma nova forma de definir a ação de governo, implica um novo modelo operativo para os atores e níveis implicados na hora de fazer política e tomar decisões. Se caracteriza pela participação, a coordenação, a cooperação e a concertação.

Parrilla-González e Palido-Fernández (2017) afirmam que a inteligência territorial integra um conjunto de conhecimentos, ferramentas e estratégias que fortalecem as capacidades de desenvolvimento de um território e a implicação dos atores no processo. Trata-se de um enfoque científico com o propósito de favorecer o surgimento de um entorno propício ao desenvolvimento territorial, tendo como uma estratégia o turismo no território.

González (2014) afirma que o contexto que permite explicar a emergência da noção de inteligência territorial distingue-se pelo intercruzamento de três fatores: (i) o reconhecimento generalizado no que se refere à informação e à comunicação; (ii) uma série de transformações socioecológicas importantes ocorridas na escala global nas últimas décadas, tais como as do tipo políticas, econômicas, ambientais e tecnológicas; (iii) a conscientização da importância do território como espaço de apropriação de recursos materiais e simbólicos, assim como de construção identitária. "Estes três fatores permitem associar o desenvolvimento de tecnologias da informação e comunicação (TIC), a gestão do conhecimento coletivo e a governança territorial” (p. 93).

Desde outra ótica, Bozzano (2013a) identifica, na noção de inteligência territorial na América Latina, três questões: (i) como uma estratégia para o desenvolvimento sustentável dos territórios; (ii) um processo baseado na construção de pessoas em sujeitos , de espaços banais em territórios, e de ideias em projetos concretos; e (iii) induz a trabalhar por identidades, necessidades e cenários futuros. Complementarmente, Almasa Maza (2010) considera os métodos e ferramentas da inteligência territorial instrumentos para reforçar os processos e lograr um estabelecimento eficiente e eficaz das políticas públicas, garantindo sua continuidade.

Bozzano (2013b), fazendo uma síntese dos aportes de vários autores, em especial latino-americanos, conceitua inteligência territorial destacando as seguintes verbalizações: (i) um projeto científico compartilhado e coconstruído entre atores territoriais e investigadores; (ii) políticas e ações orientadas à promoção do desenvolvimento dos territórios, com enfoque de investigação-ação multidisciplinar, em que interveem investigadores e atores territoriais; (iii) uma ação intencional transformadora, com enfoque no desenvolvimento duradouro, que melhore as condições de vida dos grupos sociais em seus territórios; (iv) uma forma de fazer ciência que nos permite conhecer, intervir e transformar o território com inteligência, integrando investigadores e atores territoriais; (v) um processo que se origina no campo científico e é construído juntamente com a sociedade de maneira coletiva, orientando-se ao reconhecimento das identidades, necessidades e expectativas presentes no território; e (vi) processo de intervenção no território sustentado em seis ideias força: (1) decisão - a comunidade decide coconstruir, juntamente com instituições, empresários e cientistas, o futuro desejado; (2) agenda - trabalha com agendas de transição socioecológica e transformação no território; (3) processo - processo simultâneo de transformação de pessoas em sujeitos, ideias em projetos, espaços planos em territórios multiculturais e biodiversos; (4) trânsito - de um processo de construção de conhecimento em construção de um poder socioterritorial, 
convivente com o poder político, empresários e meios de comunicação, estes contribuindo na sua divulgação; (5) propósito - promover identidades multiculturais, sonhos, expectativas e os desejos das pessoas, para que pensem e atuem na construção coletiva de um futuro melhor; (6) projeto científico - um projeto científico em desenvolvimento, com a utilização de ferramentas, métodos e técnicas para fazer projetos concretos, fundamentado numa base teórica e com status científico, mediante agendas de transição socioecológica e de transformação.

Há autores que associam os observatórios territoriais como instância da inteligência territorial. Tais observatórios, para González (2014), têm uma função central no desenvolvimento de melhores práticas e um melhor manejo do território.

Desde uma perspectiva mais ampla, os observatórios territoriais constituem instrumentos formais de geração de conhecimento territorial, pois integram uma série de ferramentas de aferição e codificação na construção de base de dados que, por meio de certos tratamentos, contextualização e sínteses, permitem gerar informação e conhecimento. Comunicar e compartilhar esta informação, assim como sua apropriação por parte de organizações e indivíduos através de sua interpretação, constituem a fase de construção coletiva do conhecimento, propósito central dos observatórios territoriais e requisito necessário no processo de aprendizagem (GONZÁLEZ, 2014, p. 99).

É possível uma síntese integrativa que apresente alguma perspectiva de avanço, considerando as abordagens teóricas sobre cidades inteligentes, internet das coisas, território inovador, na perspectiva da inteligência territorial, tanto em termos teóricos quanto de indicativos de operacionalização? Pretende-se dar um primeiro passo, neste sentido, na sequência.

\section{PARA UMA SÍNTESE INTEGRADORA}

A síntese da concepção dos diferentes autores quanto ao uso das TICs converge para um "tipo ideal" de cidades: (i) tornar as cidades mais eficientes, sustentáveis e habitáveis; (ii) melhorar a qualidade de vida e a acessibilidade de seus habitantes; (iii) assegurar um desenvolvimento sustentável, econômica, social e ambientalmente; (iv) gerar ambientes territoriais forjados por núcleos de inovação e criatividade; (v) oferecer soluções sistêmicas (integradas e interconectadas); (vi) favorecer uma mudança de comportamentos, tendo como princípio orientador a participação democrática e a pluralidade; e (vii) engendrar soluções inteligentes que favoreçam, numa ordem de prioridade, a pessoa humana.

O foco exclusivo, porém, nas cidades, não será restritivo? Entende-se que sim. Por isso, propõe-se que se atribua os qualificativos supramencionados, de igual forma, aos territórios.

Quando se utiliza a categoria conceitual território para se referir a um determinado âmbito espacial, pretende-se abarcar recortes territoriais que contemplem tanto a dimensão urbana quanto a rural, integradamente. Ou seja, pretende-se abarcar uma abordagem sistêmica, vendo os âmbitos espaciais de uma forma integradora, não setorial, tentando superar a dicotomia urbano-rural.

A Figura 1 ilustra os elementos estruturantes do que deveria vir a ser uma cidade ou território inteligente. 
Figura 1 - Elementos estruturantes de uma cidade ou território inovador

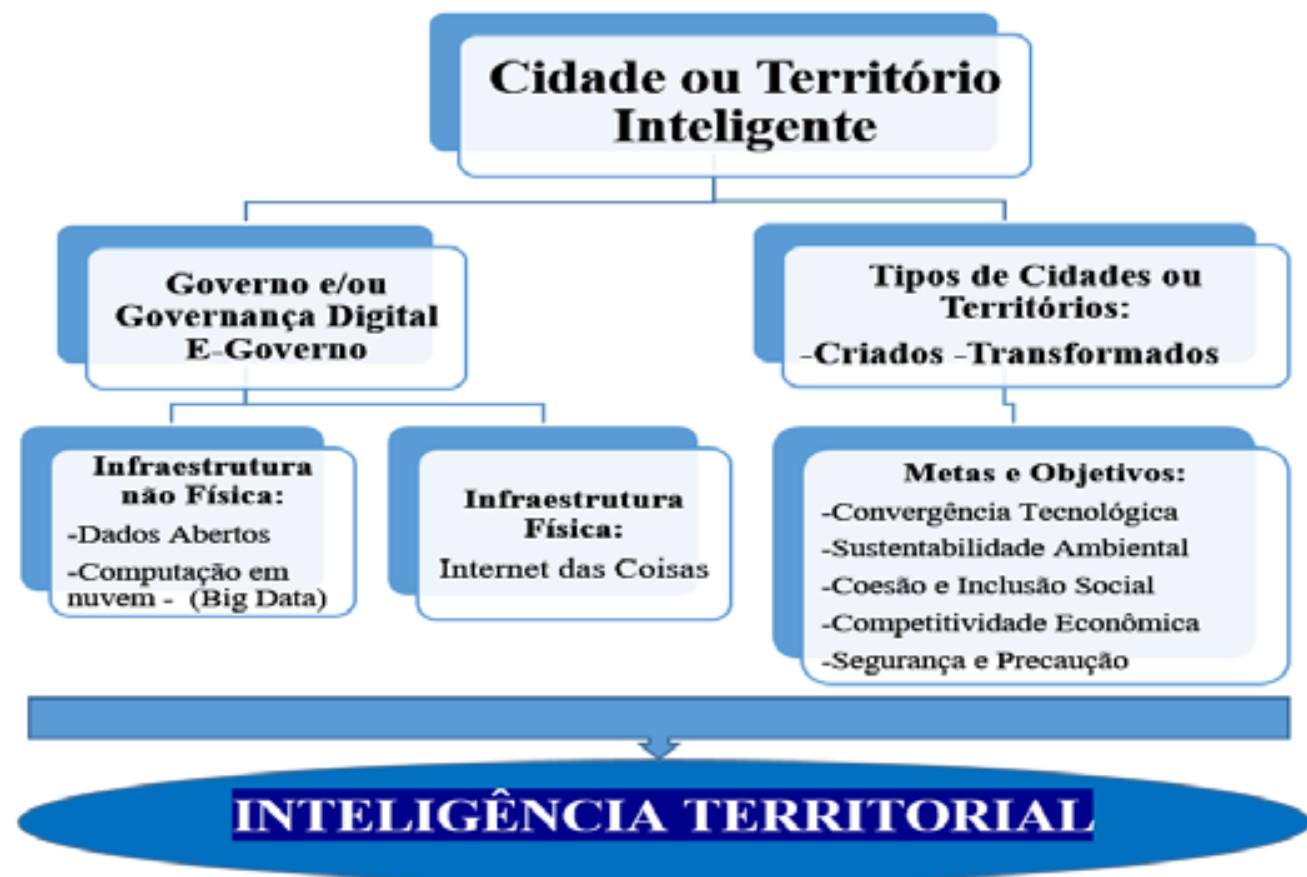

Fonte: Adaptado de Alvarado López (2018).

Na tentativa de interpretação da Figura 1, destaca-se que uma cidade ou território inteligente compreende uma dimensão operacional e outra prospectiva. Na dimensão operacional, implica que sejam pensadas estruturas de governo (por exemplo, de parte das administrações municipais) e/ou de governança (ações de planejamento e gestão territorial, envolvendo agentes governamentais e representantes da sociedade civil e do setor empresarial), que utilizem as TICs nas estruturas físicas e não físicas disponibilizadas à sociedade, tanto com qualidade suficiente quanto distribuídas equitativamente $\mathrm{e}$ disponíveis ao acesso de cidadãos e empresas. Na dimensão prospectiva, o que se espera é que as estruturas operacionais permitam a criação ou transformação de cidades ou territórios inteligentes, tendo como horizonte o atendimento de metas e objetivos prévia e colaborativamente definidos.

Na mesma linha de pensamento, Covas e Covas (2019, p. 44-45) propõem a constituição de territórios-rede inteligentes e criativos, o que implicaria: (i) uma liderança coletiva que seja capaz de suscitar o entusiasmo inicial para a ideia de uma comunidade ou território-rede desejado (T-R-D); (ii) um "território de partida" que possua alguma marca distintiva e/ou um signo distintivo territorial, a partir do qual possa irradiar mobilização e interesse; (iii) eleger um primeiro ajustamento nos limites da comunidade ou do território-rede (T-R) de partida; (iv) constituir o "ator-rede", que será o articulador do T-R; ( v) esboçar, a partir dos signos distintivos territoriais, ${ }^{21}$ uma "iconografia do T-R", que seja a base narrativa para uma estratégia de comunicação e marketing; (vi) elaborar o mapeamento dos atores principais envolvidos no projeto e suas áreas de influência; (vii) conceber uma "plataforma colaborativa interpares" para aumentar a interação e a

\footnotetext{
${ }^{21}$ Ver referências sobre o tema em: Dallabrida (2020a), Dallabrida, Baukart e Guinzani (2020) e Covas, Covas e Dallabrida (2019).
} 
conexão colaborativas entre todos os parceiros do projeto e os futuros utentes ou destinatários do projeto; (viii) elaborar "os conteúdos programáticos e o programa de ação" para a operacionalização do T-R-D; (ix) eleger os porta-vozes da verdadeira distinção territorial; e $(x)$ criar uma coreografia apropriada para o imaginário do T-R-D, por intermédio de uma estratégia de marketing e comunicação.

Na perspectiva aqui indicada, tais indicativos e perspectivas orientam o caminho para a efetividade da inteligência territorial.

Como complementação, corrobora-se a concepção teórica sobre território inovador de Gusmán (2013), que propõe um modelo de inteligência territorial, o qual se sustenta em dois grandes grupos de processos: (i) processos de produção e produtividade do conhecimento; e (ii) processos de aprendizagem territorial. "Os primeiros se baseiam na coleta e a transformação de conhecimento em inovações e os segundos trabalham na conformação do entorno e do ecossistema de conhecimento e na ampliação das possibilidades territoriais para a inovação" (p. 80). No Quadro 2 é apresentado um modelo e possíveis aspectos para sua operacionalização.

\section{Quadro 2 - Modelo conceitual de Inteligência Territorial e aspectos para sua operacionalização}

\begin{tabular}{|c|c|c|}
\hline \multicolumn{2}{|c|}{ PRODUÇÃO E PRODUTIVIDADE DO CONHECIMENTO } & $\begin{array}{l}\text { APRENDIZAGEM } \\
\text { TERRITORIAL }\end{array}$ \\
\hline $\begin{array}{l}\text { TRANSFORMAR } \\
\text { Rede de estruturação de } \\
\text { soluções }\end{array}$ & $\begin{array}{l}\text { DISTRIBUIR } \\
\text { Rede de produção e } \\
\text { agregação de valor }\end{array}$ & $\begin{array}{c}\text { APRENDER } \\
\text { Rede de Integração }\end{array}$ \\
\hline $\begin{array}{l}\text { - Proposição de soluções } \\
\text { - Gestão de recursos } \\
\text { - Gestão do portfólio de } \\
\text { projetos de inovação }\end{array}$ & $\begin{array}{l}\text { - Inovação e } \\
\text { empreendimento } \\
\text { - Transferência de tecnologia } \\
\text { - Gestão da propriedade } \\
\text { intelectual } \\
\text { - Divulgação }\end{array}$ & $\begin{array}{l}\text { - Visão de futuro } \\
\text { - Estratégia } \\
\text { - Networking } \\
\text { - Governança } \\
\text { - Gestão do conhecimento } \\
\text { regional sustentável } \\
\text { - Gestão da base de } \\
\text { conhecimento territorial }\end{array}$ \\
\hline Agentes de atuação & Agentes de atuação & Agentes de atuação \\
\hline $\begin{array}{l}\text { Administradores de projetos } \\
\text { tecnológicos, universidades e } \\
\text { centros pesquisa }\end{array}$ & $\begin{array}{l}\text { Clusters, arranjos produtivos } \\
\text { ou redes territoriais } \\
\text { de empresas, gestores } \\
\text { tecnológicos }\end{array}$ & \multirow{5}{*}{$\begin{array}{l}\text { Representação institucional e } \\
\text { organizacional do território }\end{array}$} \\
\hline \multicolumn{2}{|c|}{$\begin{array}{c}\text { ABASTECER } \\
\text { Rede de serviços de inteligência }\end{array}$} & \\
\hline \multicolumn{2}{|c|}{$\begin{array}{l}\text { - Gestão de serviços de conhecimento } \\
\text { - Prospectiva } \\
\text { - Vigilância e inteligência competitiva }\end{array}$} & \\
\hline \multicolumn{2}{|c|}{ Agentes de atuação } & \\
\hline \multicolumn{2}{|c|}{$\begin{array}{l}\text { Consultores, assessores, profissionais de vigilância e } \\
\text { inteligência, gestores e promotores do conhecimento, fontes } \\
\text { e repositórios de informação e conhecimento }\end{array}$} & \\
\hline
\end{tabular}

Fonte: Elaboração própria, com base em Gusmán (2013). 
O modelo explicitado no Quadro 2 permite imaginar-se tanto uma estrutura institucional, que pode assumir a forma de observatório territorial, quanto os agentes de atuação em cada uma das fases do processo e as ações que disso possam resultar na efetivação da perspectiva referida em relação à inteligência territorial. Não se imagina nenhum automatismo, tanto no ato de arquitetar o modelo de inteligência territorial quanto nas ações que dele possam decorrer territorialmente. Está falando-se, então, do processo de construção da dinâmica territorial do desenvolvimento.

Considera-se como indicativo básico o que pode se interpretar da argumentação de Gusmán (2013, p. 82):

O caráter dinâmico do desenvolvimento territorial se desdobra segundo as capacidades que conflagre o território para a aquisição, a exploração e estruturação de um novo conhecimento, considerando tanto os ativos de conhecimento e infraestrutura de I+D+l [investigação + desenvolvimento + inovação] de cada um dos atores territoriais, como a confiança que haja entre eles, suas capacidades de associação ou articulação e sua fortaleza institucional, cultural e política em conexão com o contexto e a aptidão do território.

A base de conhecimento demonstrada pelas capacidades, ativas ou potenciais, que existem no território, sejam eles elementos do tipo técnico ou econômico, ou elementos sociais, culturais e ambientais, constituem a inteligência territorial, social ou coletiva, que favorece - ou não, caso os elementos sejam débeis - o crescimento econômico e o desenvolvimento territorial.

Quanto às funções de uma plataforma compartilhada que represente a inteligência territorial, considere-se o que propõe Gusmán (2013): (i) habilitar a execução e a coordenação dos processos de produção e produtividade do conhecimento; (ii) facilitar o trabalho em rede (networking); (iii) integrar a base de conhecimento e as visões dos atores territoriais no que diz respeito ao uso e direcionamento em termos de desenvolvimento territorial; (iv) desencadear e dar visibilidade à estratégia territorial e o destino de recursos; e ( $v$ ) dimensionar os resultados em termos dos indicadores de competitividade, inovação e desenvolvimento.

Por fim, para inovar no processo de planejamento e gestão de um determinado recorte espacial, alguns princípios orientadores são desejáveis, para prospectar estratégias inovadoras de desenvolvimento para municípios, regiões ou territórios. Uma das inspirações possíveis para tal é o que propõe Magnaghi (2005) na operacionalização da abordagem territorial, que, segundo o autor, precisa se fundamentar em cinco movimentos: (i) definição teórico-metodológica da concepção de desenvolvimento local/regional/territorial; (ii) a definição de metodologia e técnica da representação identitária do lugar, no formato de atlas do patrimônio territorial; ${ }^{22}$ (iii) a elaboração do estatuto do lugar, ${ }^{23}$ como regras para sua transformação, ou diretrizes para a mudança; (iv) a elaboração de visões estratégicas, ou cenários de futuro, fundamentadas na valorização do patrimônio territorial, seguindo diretrizes para a mudança, previamente acordadas em

\footnotetext{
${ }^{22}$ Sobre a concepção e elementos do patrimônio territorial, sugue-se o que propõe Dallabrida (2020b).

${ }^{23} \mathrm{Ou}$ projeto político de desenvolvimento do território.
} 
espaços de concertação social, envolvendo as diferentes representações da sociedade civil, do setor empresarial e os agentes estatais; e (v) redefinição dos instrumentos e do processo de planejamento a partir da revisão dos primeiros quatro movimentos.

\section{CONSIDERAÇÕES FINAIS}

A principal contribuição pretendida por meio deste texto é avançarmos, não só teoricamente, mas também na prática da intervenção territorial, do que se espera de uma cidade inteligente ao território inteligente ou inovador para as prospecções indicativas do debate sobre inteligência territorial. Algumas implicações teórico-práticas disso decorrem.

Em primeiro lugar, falar em território inteligente e não apenas em cidades é avançarmos de uma visão espacial setorial e/ou dicotômica, por exemplo, entre espaço rural e urbano, para uma visão integradora de espaço, que se pretende transmitir na noção de território. ${ }^{24}$

Por outro lado, o território é uma totalidade complexa, onde os processos não ocorrem setorialmente, mas se intercruzam nas suas diferentes dimensões (social, econômica, ambiental, cultural, política...). Claro que implica, também, em avançarmos de um território dado para um território em construção, onde a inovação pretende ser o princípio orientador. Daí, a possibilidade de se falar em um território inteligente ou inovador.

É neste sentido que a referência à inteligência territorial é para nos darmos conta dos potenciais tangíveis e intangíveis, como o conhecimento disponível entre os atores territoriais na forma de sistema territorial, envolvendo seu patrimônio (social, cultural, produtivo, intelectual, institucional, ambiental) e o padrão operacional de seus atores e instituições a serem utilizados com o fim de engendrar um ambiente social e institucional inteligente e criativo, que possa resultar num processo inovador de desenvolvimento territorial.

Ao fim e ao cabo, o que se espera é, não apenas no discurso, mas em especial na prática, tornar ambientes de vida mais sustentáveis e habitáveis, suficientes para meIhorar a qualidade de vida de seus habitantes. Mais, engendrar ambientes territoriais orientados em práticas inovadoras pelo uso da criatividade, oferecendo soluções sistêmicas, não setoriais, logo, integradas e interconectadas.

Para tal, não basta a disponibilização e criação de tecnologias de informação e comunicação nas cidades ou territórios. $O$ que se espera são soluções inteligentes que favoreçam a pessoa humana, não apenas atendendo ao princípio da competitividade e eficácia econômica. Com certeza essas novas práticas exigem mudança de comportamento das pessoas, das instituições, das lideranças e empresários, tendo como princípio orientador a participação democrática e o respeito à pluralidade. Só assim é possível vislumbrar esperanças de que se possa enfrentar com algum sucesso o empresarialismo que impera há tempo na gestão de nossas cidades e territórios.

\footnotetext{
${ }^{24}$ Alguns autores e suas publicações contribuem para aprofundar esse tipo de concepção. Dentre os autores brasileiros contemporâneos, sugerimos dois deles, com publicações recentes: Saquet (2015); Dallabrida (2020a, b).
} 


\section{REFERÊNCIAS}

AENOR. Asociación Española de Normalización y Certificación; Comité Técnico de Normalización de Aenor - AEN/CTN 178 “Ciudades Inteligentes". [2015?]. Disponível em: https://www.aenor.com/.

ALBINO, V.; BERARDI, U.; DANGELICO, R. M. Smart cities: definitions, dimensions, performance, and initiatives. Journal of Urban Technology, v. 22, n. 1, p. 1-19, 2015.

ALVES, M. A.; DIAS, R. C.; SEIXAS, P. C. Smart Cities no Brasil e em Portugal: o estado da arte. URBE - Revista Brasileira de Gestão Urbana, v. 11, p. 1-15, 2019.

ALMASA MAZA, B. Inteligencia Territorial para una redefinición eficiente de las políticas públicas. Trabajo, Huelva, n. 23, p. 75-94, 2010.

ALVARADO LÓPEZ, R. A. Ciudad inteligente y sostenible: hacia un modelo de innovación inclusiva. Paakat: Revista de Tecnología y Sociedad, a. 7, n. 13, sept. 2017/feb. 2018.

ANGELIDOU, M. Smart city policies: a spatial approach. Cities, v. 41, p. S3-S11, 2014.

ANTONELLI, C.; J. FERRÃO (coord.). Comunicação, conhecimento colectivo e inovação. As vantagens da aglomeração geográfica. Lisboa: Imprensa de Ciências Sociais; Universidade de Lisboa, 2001.

ARES, J. M. A.; CID, R. F. Ciudad e Innovación habilitada por las TIC. In: FIGUEIREDO, A. M.; PENABAD, J. M. P.; ÁLVAREZ, E. J. V. (org.). Retos de la acción de gobierno para las ciudades del siglo XXI. Desafíos da governação das cidades do século XXI. Vigo; Porto: Eixo Atlântico do Noroeste Peninsular, 2012. p. 181-280. ARISTIZÁBAL, A. B. et al. Repensando la ciudad inteligente desde la innovación social digital ciudadana. 1. ed. Madrid: Instituto Nacional de Administración Pública, 2018. (Coleción INNAP Investiga. Serie Innovación Social).

AYDALOT, P. Milieux Innovateurs en Europe. Paris: Gremi, 1986.

BATALLA, J. M. et al. (ed.). Beyond the Internet of things: everything interconnected. Cham: Springer, 2017.

BATTY, M. et al. Smart cities of the future. Eur. Phys. J. Special Topics, 214, p. 481-518, 2012.

BENCKE, F. et al. A tríplice hélice e a construção de ambientes de inovação: o caso da Incubadora Tecnológica de Luzerna/SC. Desenvolvimento em Questão, v. 16, n. 43, p. 609-639, maio 2018.

BOZZANO, H. La geografía, útil de transformación. El método territorial, diálogo con la inteligencia territorial. Campo-Território: Revista de Geografia Agrária, v. 8, n. 16, p. 448-479, ago. $2013 a$.

BOZZANO, H. Geografia e Inteligencia Territorial: Geo-grafein, Geo-explanans, Geo-transformare. Revista Geográfica Digital, a. 10, n. 19, jan./jun. 2013b.

BOZZANO, H. (dir.) et al. Inteligencia territorial. Teoría, métodos e iniciativas en Europa y América latina. La Plata: Edulp, 2012.

CAMAGNI, R. (ed.). Innovation networks. Spatial perspectives. London: Gremi-Belhaven Press, 1995.

CARAGLIU, A.; DEL BO, C.; NIJKAMP, P. Smart Cities in Europe. Journal of Urban Technology, v. 18, n. 2, p. 65-82, abr. 2011.

CASTRO OBANDO, V. Apuntes sobre la gestión urbana en el marco de las ciudades inteligentes. Revista Centroamericana de Administración Publica, n. 72, p. 72-88, enero/jun. 2017.

CE. Comisión Europea. Smart Cities and Communities. European Innotation Partnership, 2012. Disponível em: https://wbc-rti.info/object/project/10476

COCCHIA, A. Smart, and digital city: a systematic literature review. In: DAMERI, R. P.; ROSENTHAL-SABROUX, C. (ed.). Smart city: how to create public and economic value with high technology in urban space. New York: Springer, 2014. p. 13-43.

COOKE, P. N.; MORGAN, K. The associational economy: firms, regions and innovation. Oxford: Oxford University Press, 1998.

COVAS, A. M. A.; COVAS, M. M. C. M. A inteligência dos territórios: os terroirs como espaços de inovação colaborativa. IGepec, Toledo, v. 23, Edição Especial, p. 40-54, 2019.

COVAS, A. M. A.; COVAS, M. M. C. M. A construção social dos territórios-rede: a inteligência territorial da 2a ruralidade. São Paulo: Editora LiberArs, 2014.

COVAS, A. M. A.; COVAS, M. M. C. M.; DALLABRIDA, V. R. Os signos distintivos territoriais e a smartificação do território. Uma abordagem exploratória. Biblio3W - Revista Bibliográfica de Geografía y Ciencias Sociales, v. XXIV, n. 1.268, 20 abr. 2019.

CREVOISIER, O. Industrie et région: les milieux innovateurs de l'Arc jurassien. Neuchâtel: Edes, 1993.

CUNHA, M. et al. Smart City: transformação digital de cidades. São Paulo: Programa Gestão Pública e Cidadania, 2016. 
DALLABRIDA, V. R. Governança territorial: do debate teórico à avaliação da sua prática. Análise Social, n. 215, v. L, p. 304-328, 2o trim. 2015.

DALLABRIDA, V. R. Significar territórios como estratégia de diferenciação: aportes teóricos e metodológicos. Caderno de Geografia, v. 30, n. 60, p. 196-213, 2020 a.

DALLABRIDA, V. R. Território e governança territorial, patrimônio e desenvolvimento territorial: estrutura, processo, forma e função na dinâmica territorial do desenvolvimento. G\&DR - Revista Brasileira de Gestão e Desenvolvimento Regional, v. 16, n. 2, p. 63-78, mai-ago/2020b.

DALLABRIDA, V. R. Patrimônio territorial: abordagens teóricas e indicativos metodológicos para estudos territoriais. Revista Desenvolvimento em Questão, ano 18, n. 52, p. 12-32, jul./set. 2020c.

DALLABRIDA, V. R.; BAUKART, K. S.; GUINZANI, W. Signos distintivos territoriais e indicação geográfica: uma avaliação de experiências com a aplicação de instrumental metodológico. Interações, Campo Grande, MS, v. 21, n. 1, p. 195-211, jan./mar. 2020.

DALLABRIDA, V. R.; COVAS, M. M. C. M.; COVAS, A. M. A. Inovação, desenvolvimento e espaço urbano: uma relação necessária mas não suficiente. Rev. Bras. Estud. Urbanos Reg., v. 19, n. 2, p. 360-378, maio/ ago. 2017.

DALLABRIDA, V. R.; GREIN, C. A inovação é difusa territorialmente, fato ou falácia? Estratégias de marketing territorial e branding como indicativos de inovação em municípios interioranos. Desenvolvimento, Fronteiras e Cidadania, v. 4, n. 6, 2020.

DAMERI, R. P. Searching for smart city definition: a comprehensive proposal. International Journal of Computers \& Technology, v. 11, n. 5, p. 2.544-2.551, 2013.

DE MATOS, E.; AMARAL, L. A.; HESSEL, F. Context-aware systems: technologies and challenges in internet of everything environments. In: BATALLA, J. M. et al. (ed.). Beyond the Internet of things: everything interconnected. Cham: Springer, 2017. p. 1-25.

DÍAZ-DÍAZ, R.; MUÑOZ, L.; PÉREZ-GONZALEZ, D. Business model analysis of public services operating in the smart city ecosystem: the case of Smart Santander. Future Generation Computer Systems: The International Journal of Science, n. 76, p. 198-214, 2017.

DUTTON, W. H.; BLUMLER, J. G.; KRAEMER, K. L. (eds.). Wired cities: shaping the future of communications. Washington/Boston: Washington Program Annenberg School of Commun, 1987.

EMMENDOERFER, M. L. Innovation, Brazil. In: FARAZMAND, A. (org.). Global Encyclopedia of Public Administration, Public Policy, and Governance. Cham: Springer, 2019a. p. 1-5.

EMMENDOERFER, M. L. Inovação e empreendedorismo no setor público. Brasília: Enap, $2019 \mathrm{~b}$.

EMMENDOERFER, M. L.; ASHTON, M. S. G. Territórios criativos e suas relações com o turismo. Revista Turismo \& Desenvolvimento, v. 4, n. 21, p. 459-468, 2014.

EMMENDOERFER, M. L. et al. Centro histórico como território turístico criativo: um estudo em um destino turístico internacional no Brasil. Revista Iberoamericana de Turismo-Ritur, v. 6, n. 1, p. 73-93, jan./jun. 2016.

ESTÉVEZ, E.; JANOWSKI, T. Gobierno digital, ciudadanos y ciudades inteligentes. Bit \& Byte, a. 2, p. 11-13, 2016.

ETZKOWITZ, H. Hélice tríplice: universidade-indústria-governo: inovação em ação. Porto Alegre: EDIPUCRS, 2009.

FARINÓS, J. D. Desarrollo Territorial y Gobernanza: refinando significados desde el debate teórico pensando en la práctica. Un intento de aproximación fronética. Desenvolvimento Regional em Debate, v. 5, n. 2, p. 4-24, jul./dez. 2015.

FARINÓS, J. D. Inteligencia para la gobernanza territorial. In: DE SOUZA, A. S.; SIMANCAS, M. R. (coord.). Sociedad civil organizada y desarrollo sostenible. Santa Cruz de Tenerife: Gobierno de Canarias, 2008a, p. 19-31.

FARINÓS, J. D.; SÁNCHEZ-MANJAVACAS, E. P. Hacia una nueva inteligencia territorial en la Comunitat Valenciana: Aportes desde la Cátedra de Cultura Territorial Valenciana 2016-2017. València, Espanha: Universitat de València, 2019.

FARINÓS, J. Gobernanza territorial para el desarrollo sostenible: Estado de la cuestión y agenda. Boletín de la Asociación de Geógrafos Españoles, n. 46, p. 11-32, 2008b.

FARINÓS, J. Inteligencia Territorial para la planificación y la gobernanza democráticas: los observatorios de los territorios. Proyección, v. 5, p. 45-69, 2011.

FELDMAN, P. J.; GIROLIMO, U. "Smart City": ¿nueva cara del empresarialismo urbano? Ciudades, n. 120, p. 25-33, oct./dic. 2018.

FERNÁNDEZ GONZÁLEZ, M. La Smart City como imaginario socio-técnico. 2016. Tesis (Doctorado) - Universidad del País Vasco, 2016. (Cuaderno de Investigación Urbanística, no 109, nov./dic. 2016). 
FINQUELIEVICH, S. et al. (Comp.). El futuro ya no es lo que era. 1. ed. Buenos Aires: Universidade de Buenos Aires; TeseoPress Design, 2019. 217 p.

FLORIDA, R. Toward the learning region. Futures, ano 27, n. 5, p. 527-536, 1995.

GALLAS, J. C. et al. O papel dos ativos territoriais e da inovação no desenvolvimento de cidades criativas. Desenvolvimento em Questão, ano 16, n. 43, p. 113-146, maio 2018.

GIRARDOT, J. Inteligencia Territorial y Transição Socio-Ecológica. Revista Andaluza de Relaciones Laborales, n. 23, p. 15-39, 2010.

GIRARDOT, J. Intelligence Territoriale et participation. Revue Informations, Savoirs, Décisions, Médiations, n. 16, article n. 163, 2004.

GONZÁLEZ, A. S. Inteligencia territorial y la observación colectiva Espacialidades. Revista de Temas Contemporáneos Sobre Lugares, Política y Cultura, v. 4, n. 2, p. 91-109, jul./dic. 2014.

GRAHAM, S.; MARVIN, S. Splintering urbanism. London: Routledge, 2001.

GUALLART, V. La ciudad autosuficiente. Habitar en la sociedad de la información Barcelona: RBA, 2012.

GUSMÁN, A. R. P. Propuesta de un modelo de inteligencia territorial. J. Technol. Manag. Innov., v. 8, Special Issue Altec, p. 73-86, 2013.

HAJDUK, S. The concept of a smart city in urban management. Business, Management and Education, v. 14, n. 1, p. 39-49, 2016.

HOLLANDS, R. Will the real Smart city please stand up? Intelligent, progresive or entrepreneural? City, v. 12, n. 3, Dec. 2008.

ISHIDA, T.; ISBISTER, K. Digital cities: technologies, experiences, and future perspectives. London: Springer Science \& Business Media, 2000.

JIMÉNEZ HERRERO, L. M. Hacia ciudades y territórios inteligentes, resilientes y sostenibles: gestión y gobernanza para la gran transición urbana. Madrid: Associación para la Sostenibilidad y el Progreso de las Sociedades (ASYPS), 2016.

KIM, G.-H. What is the appropriate policy direction to develop Internet of things? Journal of Multimedia Services Convergent with Art, Humanities, and Sociology, v. 6, n. 2, p. 89-100, 2016.

KOMNINOS, N. Intelligent cities: innovation, knowledge systems and digital spaces. London; New York: Taylor and Francis; Spon Press, 2002.

KOMNINOS, N. Intelligent cities and gobalisation of innovation networks. Routledge: Londres, 2008.

KOMNINOS, N. Intelligent cities: variable geometries of spatial intelligence. Intelligent Buildings International, v. 3, n. 3, p. 172- 188, 2011.

LEITE, R. P. Lugares da política e consumo de lugares: nação e patrimônio cultural. In: LEITE, R. P. Contra-usos da cidade. 2. ed. Campinas: Editora Unicamp, 2007. p. 34-95.

LUNDVALL, B. A.; JOHNSON, B. The learning economy. Journal of Industry Studies, a. 1, n. 2, p. 23-42, 1994.

MAGNAGHI, A. Presentazione. II ritorno dei luoghi nel progetto. In: MAGNAGHI, A. La rappresentazione identitaria del territorio. Atlanti, codici, figure, paradigmi per il progetto locale. Florença: Alinea Editrice, 2005. p. 7-18.

MAILLAT, D. Les milieux innovateurs. Sciences Humaines, n. 8, p. 41-57, 1995.

MATUS, R. R.; RAMÍREZ, A. R. (comp.). Ciudades Inteligentes en Iberoamérica: ejemplos de iniciativas desde el sector privado, la sociedad civil el gobierno y la academia. Ciudad de México: Infotec, 2016.

MEETHAN, K. Consuming (in) the civilized city. Annals of Tourism Research, v. 23, n. 2, p. 322-340, 1996.

MÉNDEZ, R. Innovación y desarrollo territorial: algunos debates teóricos recientes. Revista Eure, Santiago de Chile, v. XXVIII, n. 84, p. 63-83, sept. 2002.

MORA, L.; BOLICI, R.; DEAKIN, M. The first two decades of smart-city research: a bibliometric analysis. Journal of Urban Technology, n. 24(1), p. 3-27, 2017.

MOSS KANTER, R.; LITOW, S. Informed and Interconnected: A Manifesto for Smarter Cities. Harvard Business School General Management Unit Working, Paper n. 9-141, 15 June 2009. Disponível em: http:// ssrn.com/abstract=1420236.

NASCIMENTO, J. B.; SOUZA, C. L.; SERRALVO, F. A. Revisão sistemática de cidades inteligentes e internet das coisas como tópico de pesquisa. Cad. EBAPE.BR, Rio de Janeiro, v. 17, n. 4, out./dez. 2019.

PARRILLA-GONZÁLEZ, J. A.; PALIDO-FERNÁNDEZ, J. I. Inteligencia Territorial y Turismo. Hacia la integración de un modelo de transformación económica. Estudios y Perspectivas en Turismo, v. 26, p. 1-21, 2017.

PECK, J. Political economies of scale: fast policy, interscalar relations, and neoliberal workfare. Economic Geography, v. 78, n. 3, p. 331-360, 2002. 
PECK, J.; THEODORE, N. Fast policy: experimental statecraft at the thresholds of neoliberalism. Minneapolis: University of Minnesota Press, 2015.

RASSIA, S. T.; PARDALOS, P. M. Smart City networks: through the Internet of things. Cham: Springer, 2017. SAÉNZ, D. Smart Environments: las TIC en las ciudades inteligentes. Informe breve de Tendencias. [S.I.]: Instituto Tecnológico de Informática, 2011.

SÁNCHEZ CHILLÓN, P. Imaginarios globales de la innovación y el progreso: las ciudades inteligentes como instrumento narrativo para a consolidación de un nuevo poder urbano universal. Debates Latinoamericanos, Smart Cities, ano 15, n. 31, p. 68-80, oct. 2017.

SANTUCCI, G. The Internet of things: between the revolution of the Internet and the metamorphosis of objects. In: SUNDMAEKER, H. et al. (ed.). Vision and challenges for realising the Internet of things. Brussels: European Union, 2010. p. 11-24.

SAQUET, M. Por uma geografia das territorialidades e das temporalidades. Uma concepção multidimensional voltada para a cooperação e para o desenvolvimento territorial. 2. ed. rev. e ampl. Rio de Janeiro: Ed. Conseqüência, 2015.

SCHIAVO, C.; GELFUSO, A. G. Urbanismo de mercado. Las ciudades latinoamericanas y el neoliberalismo realmente existente. Cad. Metrop., São Paulo, v. 20, n. 42, p. 423-442, maio/ago. 2018.

SEIXAS, P. C. (ed.). Ativar cidades: modelos de políticas de cidades. Lisboa: Caleidoscópio, 2019. p. 7-11. SUJATA, J.; SAKSCHAM, S.; TANVI, G. Developing Smart Cities: An Integrated Framework. Procedia Computer Science, n. 93, p. 902-909, 2016.

TUROK, I. The distinctive city: pitfalls in the pursuit of differential advantage. Environment and planning $A$, v. 41, n. 1, p. 13-30, 2009.

VON STRITZKY, J.; CABRERIZO, C. Ideas para las ciudades inteligentes del futuro. Madrid: Fundación Ideas, 2011.

ZANELLA, A. et al. Internet of things for smart cities. IEEE Internet of Things Journal, v. 1, n. 1, p. 22-32, 2014.

ZUKIN, S. The Culture of Cities. $10^{\text {th }}$ ed. Oxford: Blackwell Publishers, 2010. p. 1-47. Cap. 1. 